\title{
NIOSH Center for Motor Vehicle Safety
}

\section{Performance Measures}

The NIOSH Center for Motor Vehicle Safety Strategic Plan for Research and Prevention, 2014-2018 sets performance measures for each of the Center's five strategic goals. This document serves to display progress we have made to meet these measures. The Center's team assessed current status towards meeting performance measures for each strategic goal. Each performance measure is rated as: Not Met, Partially Met, or Met or Exceeded. A Partially Met rating required funding of a project, initiating work under an existing project, or completing work addressing a part of the performance measure.

For progress highlights, a big-picture analysis of internal strengths and weaknesses and external opportunities and threats, and our plans moving forward, see the NIOSH Center for Motor Vehicle Safety Progress Report 2016. 


\section{Identify risk factors for work-related crashes}

\section{Performance Measures}

Performance Measure 1.1.1: By 2018, complete at least two research projects addressing the role of operating environment factors on work-related motor vehicle crashes. Publish results.

Performance Measure 1.1.2: By 2018, complete at least two research projects or analyses related to hours of work, long hours of driving, or fatigue to provide evidence-based recommendations, particularly for workers not covered by FMCSA regulations.

Performance Measure 1.2.1-1: By 2014, publish one methods paper on case identification and data linkage procedures in a peer-reviewed journal.

Performance Measure 1.2.1-2: By 2015, submit a second publication based on matched CFOI and FARS data to a peer-reviewed journal.

Performance Measure 1.2.1-3: By 2017, submit a third publication to a peer-reviewed journal based on analysis of matched CFOI and FARS for later data years.

Performance Measure 1.2.2-1: By 2016, initiate at least one research project to identify and evaluate sources of exposure data estimates.

Performance Measure 1.2.2-2: By 2018, if initial efforts are successful, begin to develop annual exposure estimates on work-related trips or miles traveled.

\section{Status Examples}

Law enforcement motor vehicle safety: Findings from a statewide survey [NIOSH publication]

Addressing occupational safety and health hazards in oil \& gas drilling \& servicing [Funded project]

Factors associated with truck crashes in a large cross section of commercial motor vehicle drivers [Journal article]

The influence of daily sleep patterns of commercial truck drivers on driving performance [Journal article]

Work-related fatal motor vehicle traffic crashes: Matching of 2010 data from the Census of Fatal Occupational Injuries and Fatality Analysis Reporting System [Journal article]

Performance Measures Status Key: 


\section{Identify risk factors for work-related crashes}

\begin{tabular}{|c|c|c|}
\hline Performance Measures & Status & Examples \\
\hline $\begin{array}{l}\text { Performance Measure 1.2.3: By 2018, publish } \\
\text { at least one manuscript on risk factors for work- } \\
\text { related crashes based on the analysis of naturalistic } \\
\text { driving data. }\end{array}$ & 0 & $\begin{array}{l}\text { Gap acceptance during lane changes by large-truck } \\
\text { drivers-an image based analysis } \\
\text { [Journal article] } \\
\text { The influence of daily sleep patterns of commercial } \\
\text { truck drivers on driving performance } \\
\text { [Journal article] }\end{array}$ \\
\hline $\begin{array}{l}\text { Performance Measure 1.3.1: By } 2018 \text {, influence } \\
\text { standards and regulations applicable to work-related } \\
\text { motor vehicle safety, through direct participation on } \\
\text { standards committees or contributions to responses } \\
\text { to regulatory initiatives by other agencies. }\end{array}$ & D & $\begin{array}{l}\text { Contributing to revision of American National } \\
\text { Standards Institute/American Society of Safety } \\
\text { Engineers (ANSI/ASSE) Z15.1 standard, Safe Practices } \\
\text { for Motor Vehicle Operations. } \\
\text { Data from the NIOSH National Survey of Long-haul } \\
\text { Truck Driver Health and Injury supported Federal } \\
\text { Motor Carrier Safety Administration rulemaking to } \\
\text { require seat belt use by all passengers in large trucks. }\end{array}$ \\
\hline
\end{tabular}

Performance Measures Status Key: 


\section{Performance Measures \\ Performance Measure 2.1.1: By 2018, develop and disseminate materials on the responses of specialized work vehicle operators to driver assistance systems or road safety information systems, and the criteria for effective systems.}

Performance Measure 2.1.2: By 2018, transfer new knowledge and best practices on at least two effective interventions on driver assistance or road safety information systems to manufacturers and organizations that use specialized work vehicles.

Performance Measure 2.1.3: By 2018, develop and disseminate materials on practices used by specialized work vehicle operators to acquire information on intersection configurations and make decisions on maneuvering through intersections and traffic light systems.

Performance Measure 2.1.4: By 2018, transfer new knowledge and best practices on at least two effective interventions on driving assistance systems or road safety information systems associated with intersection safety to manufacturers of specialized work vehicles and organizations that use them, to reduce intersection crash incidents.

Performance Measure 2.2.1-1: By 2014 and 2018, establish national anthropometric databases of fire fighters and emergency medical services personnel, respectively.

Performance Measure 2.2.1-2: By 2015, develop and disseminate a sourcebook to assist users of the national anthropometric database of truck drivers.

Performance Measure 2.2.2: By 2016, develop and disseminate materials on at least two improved interventions for fire apparatus.

\section{Status Examples}

Reducing firefighter vehicle crashes: Simulation and intervention [Funded project]

Best-practice guidelines for occupational driver safety at intersections [Funded project]

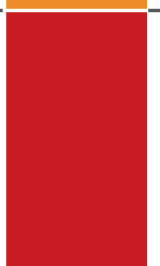

$$
\text { safety at intersections [Funded project] }
$$

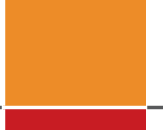

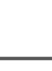




\section{Apply engineering and technology-based safety interventions}

\section{Performance Measures}

Performance Measure 2.2.3: By 2017, transfer at least two human factors engineering recommendations or interventions to improve the design of fire apparatus, use of protective measures, and standards/specifications for fire apparatus.

Performance Measure 2.3.1: By 2015, complete impact tests and update crashworthiness data related to biomechanical loading and injury risk to occupants of at least one type of specialized work vehicle.

Performance Measure 2.3.2: By 2017, develop guidelines and at least three engineering recommendations to reduce biomechanical loading and injury risk to occupants during crash and rollover incidents of at least one type of specialized work vehicle.

Performance Measure 2.3.3: By 2017, transfer at least two human factors engineering recommendations or vehicle configuration improvements into safety standards/specifications for at least one type of specialized work vehicle.

Performance Measure 2.4.1: By 2017, publish a document on new technologies found in vehicles used for work purposes, challenges and risks associated with introducing these technologies, and research ideas on best safety practices.

Performance Measure 2.4.2: By 2016, initiate at least one research project assessing the effectiveness of automated vehicle functions or connected-vehicle technologies for reducing crash risk for specialized work vehicles.

\section{Status Examples}

Guidelines and standards incorporating NIOSH anthropometry data:

National Fire Protection Association Automotive Fire Apparatus Standard 1901

Two fire apparatus manufacturers are prototyping new designs based on NIOSH recommendations.

Impact and crashworthiness testing used to develop guidelines shown for Performance Measures 2.3.2 and 2.3.3.

Guidelines and standards incorporating NIOSH crash test data:

General Services Administration Star-of-Life

Ambulance Purchase Specification, KKK-A-1822F, Change Notice 9 (2016)

National Fire Protection Association Automotive Ambulance Standard, NFPA 1917 2nd Edition (2016)

Commission for Ambulance Accreditation Services (CAAS) Ground Vehicle Standard GVS V1.0 (2016)

Influenced publication of SAE Ambulance Patient Compartment Seating Integrity and Occupant Restraint standard.

Influenced publication of SAE Ambulance Litter Integrity, Retention, and Patient Restraint standard.

Performance Measures Status Key: 


\section{Promote evidence-based policies, standards, and regulations}

\section{Performance Measures \\ Performance Measure 3.1.1: By 2016, initiate at least two research projects to assess the effectiveness of road safety interventions.}

Performance Measure 3.1.2: By 2016, publish a peer-reviewed paper and one journal article to report driver training methods evaluation results.

Performance Measure 3.1.3: By 2016, initiate at least one research project to assess safety climate and culture as determinants of workplace road safety intervention success or failure.

Performance Measure 3.1.4: By 2018, initiate research to validate fleet safety management audit tools.

Performance Measure 3.2.1: By 2016, develop a guide to help employers justify the economic and occupational safety benefits of a motor vehicle safety program.

Performance Measure 3.2.2: By 2016, develop and distribute tools to support monitoring of workplace road safety performance.

Performance Measure 3.2.3: By 2017, initiate a project to assess the integration of motor-vehicle safety management programs into occupational safety and health management systems.

Performance Measure 3.2.4: By 2018, publish a peer-reviewed paper and one journal article to report the results of economic research on road safety management programs.

Performance Measure 3.3.1: By 2018, incorporate $\mathrm{NIOSH}$ input into fleet safety management standard revisions to either ANSI Z15.1 or ISO 39001.

\section{Status Examples}

Analysis of company fleet safety management data to guide research and prevention [Funded project] Reducing road risk using journey management [Conference paper]

Online training for law enforcement to reduce risks associated with shift work and long work hours [Funded project]

Analysis of company fleet safety management data to guide research and prevention [Funded project]

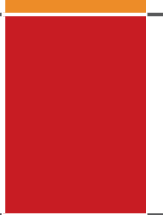

Business case calculator for road safety strategies [Funded project]
Contributing to revision of American National Standards Institute/American Society of Safety Engineers (ANSI/ASSE) Z15. 1 standard, Safe Practices for Motor Vehicle Operations.

Served on the U.S. committee for the International Organization for Standardization (ISO) 39001 standard, Road-Traffic Safety Management Systems Requirements and Guidance for Use.

Performance Measures Status Key: 


\section{Collaborate with global partners}

\section{Performance Measures}

Performance Measure 4.1.1-1: Strengthen research coordination through international organizations and nongovernmental organizations with global reach.

\section{Performance Measure 4.1.1-2: Expand} collaborations to developing nations and emerging markets.

Performance Measure 4.1.2-1: Establish partnerships for translation of NIOSH publications to other languages.

Performance Measure 4.1.2-2: By 2018, regularly update social media channels with new and noteworthy research results and injury prevention messages for global stakeholders.

Performance Measure 4.1.3-1: Strengthen participation in globally-recognized organizations.

\section{Status Examples}

Worked with the Institute of Road Traffic Education in India to evaluate training for heavy-goods vehicle drivers and build capacity for fleet safety management by transport operators.

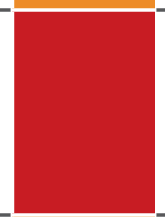

CDC Business Pulse: Motor vehicle safety at work [In progress; CDC Foundation publication]

NETS' Comprehensive Guide to Road Safety ${ }^{\mathrm{TM}}$

Promote work-related road safety globally in support of the UN Decade of Action for Road Safety 2011-2020 as a member in the UN Road Safety Collaboration.

Served on the U.S. committee for the International Organization for Standardization (ISO) 39001 standard, Road-Traffic Safety Management Systems - Requirements and Guidance for Use.

Performance Measure 4.2.1: By 2016, publish a peer-reviewed paper comparing sources of data on work-related crashes around the world.

Performance Measure 4.2.2: By 2016, publish at least two peer-reviewed papers on truck driver safety in India.

Performance Measures Status Key: 


\section{Communicate safety and policy recommendations}

\section{Performance Measures}

Performance Measure 5.1.1-1: By 2014, use one social media channel to communicate research results and injury prevention messages.

Performance Measure 5.1.1-2: By 2015, use at least three social media channels to communicate research results and injury prevention messages.

Performance Measure 5.1.1-3: By 2018, regularly update social media channels with new and noteworthy research results and injury prevention messages.

Performance Measure 5.1.2: By 2015, publish first eNewsletter to external stakeholders.

Performance Measure 5.1.3: By 2015, publish redesigned "Motor Vehicle Safety" webpage.

Performance Measure 5.1.4: By 2015, prepare an audience analysis for NIOSH information products on prevention of work-related crashes.

Performance Measure 5.2.1: By 2016, incorporate collaborative research and prevention activities into existing agreements with at least two partners, or initiate new agreements.

Performance Measure 5.2.2: By 2015, summarize the results of one NIOSH research study to disseminate through communication channels of trade associations and professional organizations.

\section{Status Examples}

@NIOSH MVSafety [Twitter]

National Institute for Occupational Safety and Health [Facebook]

$@$ @IOSH MVSafety [Twitter]

nioshusa [Instagram]

How employers can keep older drivers safe at work

[NIOSH Science Blog]

\#DriveSafe4Life [Twitter chat]

Behind the Wheel at Work [eNewsletter]

Motor vehicle safety at work directory [Webpage]

NIOSH Center for Motor Vehicle Safety: Needs assessment and audience analysis [Funded project]

Working with the U.S. Bureau of Labor Statistics to analyze matched data to identify and characterize risk factors for U.S. fatal occupational motor vehicle crashes.

Working with the National Highway Traffic Safety Administration to strengthen workplace crash data and enhance motor vehicle safety of emergency responders.

Research in brief: Motor vehicle safety for law enforcement officers- Still a priority [Journal Article]

Performance Measures Status Key: 